\title{
ARCHITEKTUR UND STÄDTEBAU IM GETEILTEN POLEN DES 19. JAHRHUNDERTS IM POLITISCHEN KONTEXT ${ }^{1}$
}

\author{
Peter Stachel charakterisierte jüngst in einem instruktiven Aufsatz \\ den öffentlichen Raum wie folgt:
}

Mit der Herausbildung einer politischen Öffentlichkeit in Verbindung mit beschleunigten Urbanisierungsprozessen, zunehmender politischer Partizipation und Bürgerkultur sowie der einsetzenden Nationalisierung der Massen seit Ausgang des 18. Jahrhunderts und der damit verbundenen Vorstellung von einer gleichsam „natürlichen” Einheit von ethnischer Gruppe und Territorium, erfuhren die Formen der politischen Inszenierung in Europa einen grundlegenden Wandel. Der öffentliche Raum diente fortan nicht mehr nur der Repräsentation von Herrschaft, sondern wurde in zunehmendem Maße für die Manifestation kollektiver Identifikationsprogramme genutzt und entwickelte sich so im Laufe der Zeit zu einem oftmals auch kontrovers beanspruchten Forum und Austragungsort unterschiedlicher politischer Vorstellungen und Imaginationen.(...) Im östlichen Europa war die als Ideal betrachtete Einheit von Ethnie und Territorium (...) nicht gegeben und auch nicht ohne Gewaltanwendung herzustellen. Hier waren eindeutige symbolische Festlegungen daher zwangsläufig mit vielerlei Irritationen und oft mit Konflikten verbunden. Eine Häufung von Mehrfachkodierungen und Mehrfachbeanspruchungen bei gleichzeitig exklusiv vorgetragenen Besetzungsansprüchen führte unvermeidlich zu disparaten und manchmal ausgesprochen feindselig gegeneinander gerichteten Lesearten ${ }^{2}$.

Eine so verstandene Öffentlichkeit spiegelt sich in der Architektur der polnischen Städte wider und ist ein wichtiges, wenngleich relativ wenig erforschtes Thema, das unter den Begriffen „politische Architek-

1 Dieser Artikel ist im Rahmen der Forschung zur Eroberung der City. Politische Architektur in Mitteleuropa 1815-1918 entstanden, die ich in den Jahren 2011/2012 während des Forschungsaufenthalts am FRIAS an der Albert-Ludwig-Universität in Freiburg/Br. durchführen konnte.

2 P. Stachel, Stadtpläne als Zeichensysteme. Symbolische Einschreibungen in den öffentlichen Raum, (in:) R. Jaworski, P. Stachel (Hg.), Die Besetzung des öffentlichen Raumes. Politische Plätze, Denkmäler und Straßennamen im europäischen Vergleich, Berlin 2007, S. 20, 21. 
tur” und „politische Stadträume”3 hier am Beispiel von Posen, Warschau und Krakau diskutiert wird. Gezeigt werden soll, dass man die Architektur dieser drei Städte im Rahmen der preußischen, russischen und österreichischen „inneren Kolonisation” neu kontextualisieren kann.

Die genannten Städte waren auf Grund der Teilungen Polens in neue Staatssysteme eingegliedert worden. Nach dem Wiener Kongress zu Regierungssitzen bzw. Provinzhauptstädten erklärt, wurden sie meistens nicht als offene Städte belassen, sondern in das Korsett stark ausgebauter Festungssysteme eingeschlossen und erst nach 1900 entfestigt. Diese gefängnisartige territoriale Situation hatte - im Hinblick auf die jeweilige komplizierte ethnische und nationale Konstellation - einen besonderen Einfluss auf die Formierung der politischen Stadträume und der politischen Architektur. Diese Städte sind vor allem durch verschiedene Strategien der jeweiligen politischen und gesellschaftlichen Kräfte zum Bau und Gegenbau, Deutung und Gegendeutung, Öffentlichkeit und Gegenöffentlichkeit gekennzeichnet. Die staatliche, bürgerliche, aber auch kirchliche Selbstdarstellung (beiderseits, d.h. polnisch versus preußisch, russisch und österreichisch) agierte hier mit signifikanten Strategien. Die Demonstration von Kraft und Macht der jeweiligen Regierungen stieß häufig auf eine kodierte „sprechende Architektur” und Symbolik. Diese wurde durch die dem fremden Staat untergeordneten Bevölkerungsgruppen geschaffen. Dies führte oft zu einer gründlichen Umgestaltung und einer neuen Bedeutungshierarchisierung des öffentlichen Raums, wobei sowohl Machthaber als auch die einheimische Bevölkerung nach einer eigenen Architektursprache suchten. Dies spiegelte sich u.a. in der Form und gewählten Dekoration (Skulptur, Malerei) sowie der bevorzugten Stilistik (z.B. Neugotik, Neorenaissance) wider, die mit der eigenen Geschichte und Tradition assoziiert wurden. Monumentale Bauwerke, die im 19. Jh. in diesen Städten errichtet wurden oder gebaut werden sollten (viele dieser Vorhaben blieben unverwirklicht), waren als „politische Architektur” jeweils national konzipiert. Sie eigneten sich den wichtigsten Teil des Stadtraums an, indem sie neue Strukturen von ausgebauter Symbolik und Ikonographie bildeten. Jede historische Epoche hat eigene Werke in den öffentlichen Raum hineingeschoben, so dass er

3 Die Begriffe „politische Architektur” und „politische Räume” hat in die kunstgeschichtliche Forschung vor allem Martin Warnke eingeführt. Vgl. M. Warnke (Hg.), Politische Architektur in Europa vom Mittelalter bis heute - Repräsentation und Gemeinschaft, Köln 1983 sowie W. Gottschall, Politische Architektur. Begriffliche Bausteine zur soziologischen Analyse des Staates, Bern, Frankfurt am Main, New York, Paris 1987; H. Hipp, E. Seidl (Hg.), Architektur als politische Kultur. Philosophia Practica, Berlin 1996; A. Nova, C. Jöchner (Hg.), Platz und Territorium. Urbane Struktur gestaltet politische Räume, München 2010. 
als Palimpsest zu lesen ist, in dem sich verschiedene Deutungen aufeinander schichten, überlagern und überschreiben. Jede Änderung der politischen, sozialen, kulturellen etc. Situation, jedes neues Gebäude und Denkmal, jede neue Fassade und Dekoration sowie neue Innenräume konnten diesen Raum mit neuen Bedeutungen versehen. Dazu gehörte die Inszenierung des Raumes mittels politischer Demonstrationen und Straßenkämpfe, Militärparaden und königlichen Festzügen, Begräbnissen bedeutender Persönlichkeiten und Nationalhelden sowie kirchlicher Prozessionen und Musik (wie z.B. Kirchenglocken), die den Raum zwischen den architektonischen Fassaden füllten, mit neuen Identifikationsbedeutungen versahen, wesentlich umgestalteten und immer neu kodierten und aktualisierten. Man kann sagen: Der politische Stadtraum ähnelt im zeitlichen Verlauf einem Kaleidoskop. Es ist im ständigen Wechsel und nie wiederholt sich ein Bild. Jede Schicht zu dechiffrieren und zu dekodieren, die Räume und Architektur als nichtschriftliche Quelle zu lesen und zu verstehen, kann zu einem genaueren Verstehen von Geschichte, Gesellschaft und Kultur beitragen.

Für die Erforschung der Stadträume der polnischen Städte sind folgende Fragen wesentlich:

1. Wie wurde die Architektur- und Städtebauentwicklung in den jeweiligen Städten durch die Politik und Macht der fremden Regierung beeinflusst? Wie spiegelte sich die imperiale und koloniale Herrschaft des Zarenreiches, des wilhelminischen Kaisertums und der Habsburgermonarchie in der Gestaltung der politischen Territorien wider?

2. In welche Räume und Orte von gegensätzlicher symbolischer Bedeutung, die die einheimische und fremde Kommunikation bzw. Kräfteverhältnisse charakterisieren, ist die Stadt geteilt? Welche Stadträume definieren Mittelpunkte (Zentren) politischen Handelns? In welchem Teil der Stadt und in welchen städtebaulichen Kontext sind sie situiert, durch welche Bauten und Funktionen sind sie dominiert bzw. charakterisiert (Regierungsbauten, öffentliche Gebäude, sakrale Bauten, Militärbauten, Wohnanlagen, Denkmäler etc.), wie haben sie die Gegend geprägt und welche Veränderungen im städtischen Bild hat ihr Entstehen hervorgerufen?

3. Wie und in welcher Form spiegelt sich das Ringen der politisch konkurrierenden Kräfte um die ästhetische Kontrolle der zentralen öffentlichen Orte wider, wodurch zeichnen sich Form und Stilistik der „sprechenden” Objekte aus? Die kodierte Dekoration der einheimischen Bauten wäre als „eine geheime Sprache” anzusehen, derer Botschaft nur „Eingeweihten” verständlich oder sogar 
selbstverständlich war. Dagegen manifestierte sich die Machtdemonstration des Staates mit besonderer Aussagekraft in den Repräsentationsbauten und wurde als Medium politischer Symbolik in nicht zu übersehender Weise eingesetzt.

4. Wie verlief die Besetzung des städtischen Raumes im 19. Jahrhundert in den drei Teilungsgebieten Polens? Wo liegen die Gemeinsamkeiten, wo die Unterschiede? Wie wurde architektonisch und städtebaulich ,gesprochen”, und wie wurde die Dechiffrierung dieser Sprache in der Öffentlichkeit rezipiert?

Diese Leitfragen bilden den Ausgangspunkt für eine neue Interpretation der Architektur- und Städtebaugeschichte im geteilten Polen im 19. Jahrhundert ${ }^{4}$, wobei im Folgenden nur einige der genannten Aspekte behandelt werden können.

Erste Maßnahmen, die die neuen Staatsmächte in den einverleibten Territorien noch im 18. Jahrhundert ergriffen, waren durch eine zivilisatorische und kulturelle Mission gekennzeichnet. Sie waren von besonderer Bedeutung, da sie die Grundlagen für die städtebauliche Entwicklung im nächsten Jahrhundert und die Aufteilung der Stadt in gute und schlechte sowie einheimische und fremde Gegenden schufen. Für das Mapping der neuerworbenen Länder ist die militärische Karte von Galizien von enormer Bedeutung 5 und die Aktualisierung der Stadtpläne dienten der Idee, den bestehenden Raum neu zu strukturieren und in den Städten Wohngebiete vor allem für ankommende Beamte und Offiziere zu schaffen. In Lemberg (ab ca. 1777), Posen (ab ca. 1794) und in Krakau (ab ca. 1800) sowie in kleineren Städten wie z.B. in Płock ${ }^{6}$ wurde

${ }^{4}$ Auch unter diesem Aspekt wurde polnische Architektur komplementär bisher nicht analysiert. Vgl. K. Stefański, Architektura XIX wieku na ziemiach polskich, Łódź 2005.

5 W. Bukowski, A. Janeczek, Mapa józefińska Galicji (1779-1783) w przededniu edycji. Przedmiot $i$ założenia programu wydawniczego, „Studia Geohistorica”, Jg. 1, Nr 1 (2013), S. 91-112; Z. Budzyński, W. Bukowski, B. Dybaś, A. Janeczek, Z. Noga (Hg.), Galicja na józefińskiej mapie topograficznej 1779-1783. Die Josephinische Landesaufnahme von Galizien 1779-1783, Bisher sind folgende Bände erschienen: Bd. 1, Teil A, B, Kraków 2012, Bd. 2 Teil A, B, Kraków 2013, Bd. 4, Teil A, B, Kraków 2012; Bd. 5, Teil A, B, Kraków 2015.

6 T.J. Żuchowski, David Gilly und die Ostgebiete Preußens, (in:) E. Führ, A. Teut (Hg.), David Gilly - Erneurer der Baukunst, Münster, New York, München, Berlin 2008, S. 61-78; J. Drejer, Im Dienst des Staates in Süd- und Neuostpreußen. Der Anteil der preuBischen Architekten und Stadtplaner an der Erneuerung der polnischen Städte in den Jahren 1793-1806. Mit einer Fallstudie über Płock in Masowien, Frankfurt (Oder), 2012 [Hochschulschrift: Frankfurt (O), Europa-Universität, Diss., 2009, im Druck]. T.J. Żuchowski, Der Einfluss der preußischen Stadtbaukunst auf die städtebauliche Entwicklung Posens, (in:) Ch. Baier, A. Bischoff, J. Drejer, U. Reinisch, T. Żuchowski (Hg.), Retablissement. Preußische Stadtbaukunst in Polen und Deutschland, Berlin 2016, S. 279-289. 
dies zuerst durch die Beseitigung der Stadtmauer und Anlegung von Promenaden sowie dazu gehörender repräsentativer Plätze, Boulevards oder sogar von Vorstädten, wie in Posen, realisiert. Damit begann die Zersplitterung der Wohngebiete: Altstädte, die für die neuen Behörden zu schmutzig, zu dicht bebaut und unhygienisch waren, blieben anfangs nur der einheimischen Bevölkerung (Polen und Juden) vorbehalten, während repräsentative, nach den aktuellen ästhetischen und hygienischen Normen geplante Wohnanlagen, häufig von hauptstädtischen Architekten geplant, den Kern des durch Fremde besetzten Territoriums bildeten. Die separaten Wohngebiete wurden immer in gesunde, offene und mit Grünanlagen versehene Räume verschoben, die außerhalb der befestigten Stadt lagen. Promenaden auf dem ehemaligen Glacis, meist mit hohen Pappeln bepflanzt, markierten deutlich eine neue visuelle und im gewissen Sinne nationale Grenze zwischen den alten (einheimischen) und neuen (fremden) Stadtteilen. Die Fremdheit der neuen Vorstädte wurde durch die Errichtung von Regierungsbauten, Kasernen und Gefängnissen, aber auch öffentliche Einrichtungen wie Theatern geprägt, die der Festigung der neuen Macht und Entfaltung des (neuen) kulturellen Lebens dienen sollten. Die österreichische und preußische städtebauliche und architektonische Tätigkeit in der ersten Teilungsperiode, d.h. in Galizien ab 1772 und in Südpreußen ab 1793 bis 1807 ist als eine Aufklärungsmission zu verstehen, die der Einverleibung der Territorien und Schaffung neuer administrativer, militärischer und sozialer Strukturen in Kolonien glich. Die bisherige Forschung sah die Erweiterung der habsburgischen Monarchie sowie Preußens durch die polnischen Gebiete nur selten in diesem Kontext. Wenn man jedoch diese Prozesse in postkolonialer Perspektive untersucht, scheint die Integration Galiziens und Großpolens sowie nach 1831 auch des Königreichs Polen als ein frappierendes Beispiel der inneren Kolonisation, die in den darauffolgenden Dezennien erweitert und intensiviert wurde ${ }^{7}$. Eine genaue Analyse der

7 In diesem Kontext wurde die Architektur im geteilten Polen im 19. Jahrhundert bisher nicht dargestellt, obwohl die historische Forschung auf diese Problematik, insbesondere die Galizienforschung, oft verweist. Vgl. K. Kaps, Ungleiche Entwicklung in Zentraleuropa. Galizien zwischen überregionaler Verflechtung und imperialer Politik (17721914), Wien, Köln, Weimar 2015. Auch: M. Rolf, Imperiale Herrschaft im Weichselland. Das Königreich Polen im russischen Imperium (1864-1915), Berlin, München, Boston 2015; Th. Serrier, Provinz Posen, Ostmark, Wielkopolska. Eine Grenzregion zwischen Deutschen und Polen 1848-1914, Marburg 2005; R. Gehrke, Das „räuberische Monstrum”: Preußen in der polnischen Historiographie des 19. und frühen 20. Jahrhunderts, (in:) W. Neugebauer (Hg.), Das Thema Preußen in Wissenschaft und Wissenschaftspolitik des 19. und 20. Jahrhunderts, Berlin 2006 (Forschungen zur Brandenburgischen und Preußischen Geschichte N.F. Beiheft 8), S. 205-229. 
räumlichen Entwicklung sowie der neugebauten Architektur im geteilten Polen im 19. Jahrhundert schafft neue Forschungsperspektiven nicht nur für die polnische Geschichte, sondern auch für ihren mitteleuropäischen Kontext.

Posen ist dafür das beste Beispiel. Im Gefolge der zweiten Teilung Polens 1793 fiel Großpolen - Wielkopolska, eine wohlhabende und wirtschaftlich hoch entwickelte Region des Landes - an Preußen. Seitdem war in Posen der preußische Staat der Hauptinvestor, und die Entscheidungen bezüglich der Stadtentwicklung wurden meistens in Berlin getroffen. Sie trafen auf den Widerstand des starken und politisch bewussten polnischen Adels sowie der katholischen Kirche, die sich als „Wächter des Polentums und der Tradition" verstanden. Für die neuen preußischen Behörden waren sie - als Bauinitiatoren und Bauinvestoren - reelle und ernste „Gegner”.

Kurz nach der Einnahme Posens wurden in den 1790er Jahren grundlegende Raumveränderungen in der Stadt realisiert. Sie hingen mit der partiell durchgeführten Entfestigung und der Gründung eines neuen Stadtviertels zusammen. Die modern entworfene Obere Stadt entsprach den neuesten Trends des europäischen Städtebaus ${ }^{8}$. Sie besaß eine breite Promenade und einen groß angelegten Platz, an dem 1802 ein Schauspielhaus in Formen des strengen Berliner Klassizismus errichtet wurde (Friedrich Gilly). Hier sollten vornehme Häuser deutscher Beamten und Militärs entstehen, und das Theater war vor allem für das deutsche Publikum gedacht. Die Versuche, daneben ein polnisches Schauspielhaus zu bauen, misslangen. Somit zeichnete sich bereits zu Beginn der preußischen Herrschaft in Posen in diesem modern konzipierten Stadtraum ein nationaler Konflikt ab. Er prägte die Architektur, die in den kommenden Jahrzehnten um den Platz herum entstand.

Nach 1815, als Posen preußische Provinzhauptstadt geworden war, gingen deutsche Bauinitiativen vor allem aus militärischen Kreisen hervor, die für die Umgestaltung der Stadt in eine Festung plädierten. Die polnische Initiative lag dagegen bei den Großadeligen, die Posen als Kulturstadt im Sinne eines „neuen Athens” ansahen. Zur Schaubühne des architektonischen Streites wurde der neu angelegte Wilhelmsplatz. In der ersten Hälfte des 19. Jahrhunderts entstanden hier abwechselnd Sitze deutscher und polnischer Einrichtungen. Neben dem deutschen

8 Zur Entwicklung der Architektur in Posen mit einer gründlichen Analyse der hier besprochenen Bauten vgl. Z. Ostrowska-Kębłowska, Architektura i budownictwo w Poznaniu $w$ latach 1780-1880, Poznań 2009, insbes. S. 116-125, 138-145, 166-178, 192-207, 331337. Auch A. Zabłocka-Kos, Breslau und Posen im 19. Jahrhundert: zwei Regierungsstädte - zwei Welten, (in:) J. Luh, V. Czech, V. Becker (Hg.), Preussen, Deutschland und Europa 1701-2001, Groningen 2003, S. 313-337. 
Theater stiftete der Aristokrat Edward Raczyński ${ }^{9}$ eine polnische Bibliothek (Architekt unbekannt, 1829). Sie diente als Ersatz für polnische Kultur- und Wissenschaftsinstitute, deren Gründung von den preußischen Behörden untersagt wurde. In der Form seiner Fassade knüpfte das Gebäude sichtbar an die Louvre-Ostfassade an. Die Bauart dieses Objekts stand somit mit dem benachbarten deutschen Schauspielhaus im Wettstreit, indem sie sich von den Berliner Kunsttrends deutlich unterschied und auf Frankreich als einem polenfreundlichen Staat verwies. Etwas später wurden im Hauptteil des Platzes zwei Sitze militärischer Einrichtungen errichtet. Der polnischen Seite gelang es im Gegenzug, ein modernes palastartiges Hotel „Bazar” (1837-1841) zu errichten, das auch als Sitz der polnischen Vereine diente. Bald erklärten es die preußischen Behörden zum „Hort der polnischen Sehnsüchte nach Souveränität”.

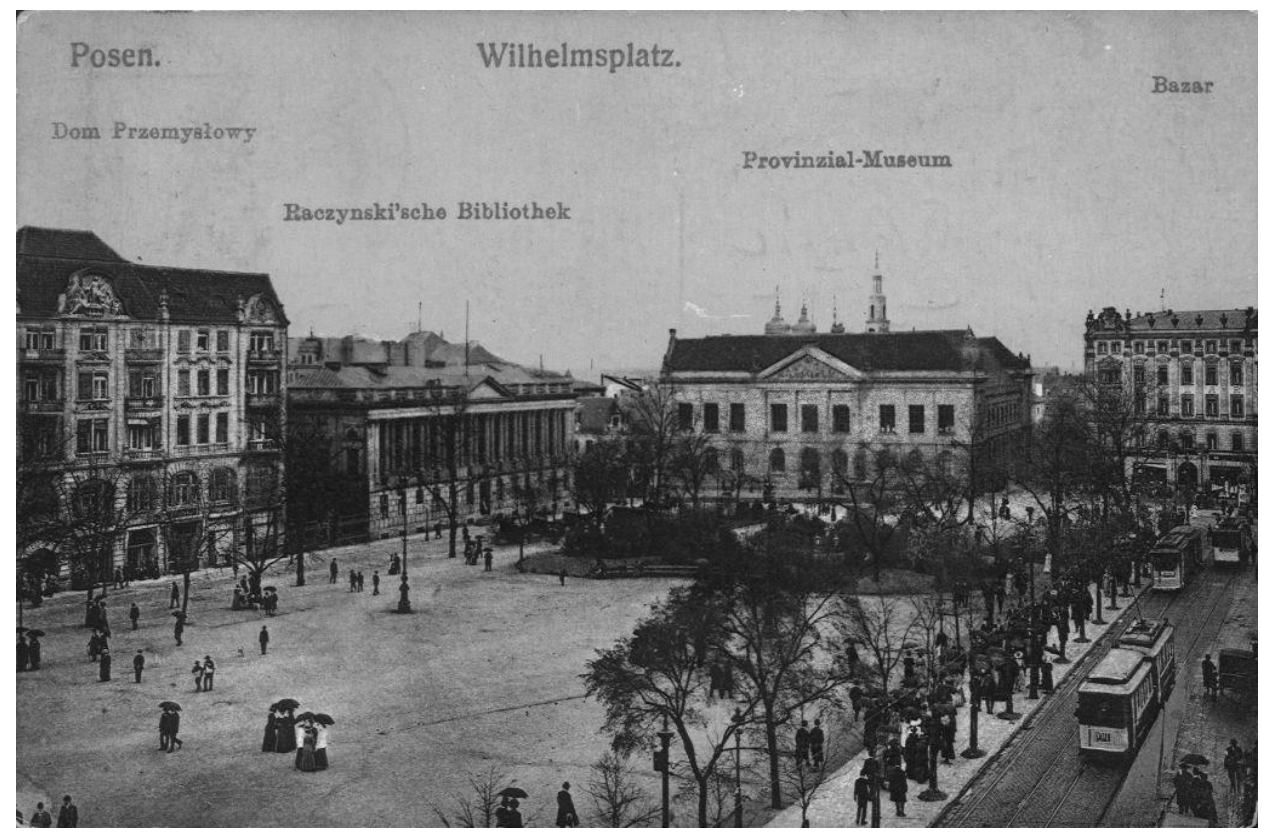

1. Posen, Wilhelmsplatz. Postkarte um 1900. Biblioteka Uniwersytecka Poznań

Ein außenstehender und stadtgeschichtsunkundiger Betrachter konnte feststellen, dass das neue Zentrum am Posener Wilhelmsplatz den repräsentativen europäischen Plätzen ähnelte, die anstelle der ehemaligen Befestigungen angelegt wurden. Schauspielhäuser, Biblio-

9 W. Suchocki, M. Mencfel, A.S. Labuda (Hg.), Edward i Adam Raczyńscy: dzieła osobowości - wybory - epoka. Edward und Atanazy Raczyński: Werke - Persönlichkeiten - Bekenntnisse - Epoche, Poznań 2010. 
theken, Hotels sowie Gebäude staatlicher Einrichtungen und Behörden gehörten zum klassischen Ensemble öffentlicher Gebäude, die an derartigen Plätzen und repräsentativen Straßenzügen situiert wurden, wie zum Beispiel am Augustusplatz in Leipzig oder an der Ludwigstraße in München. Die Architektur der Posener Bauten wich auch im Wesentlichen nicht von den künstlerischen Konzepten ab, die in anderen europäischen Städten realisiert wurden.

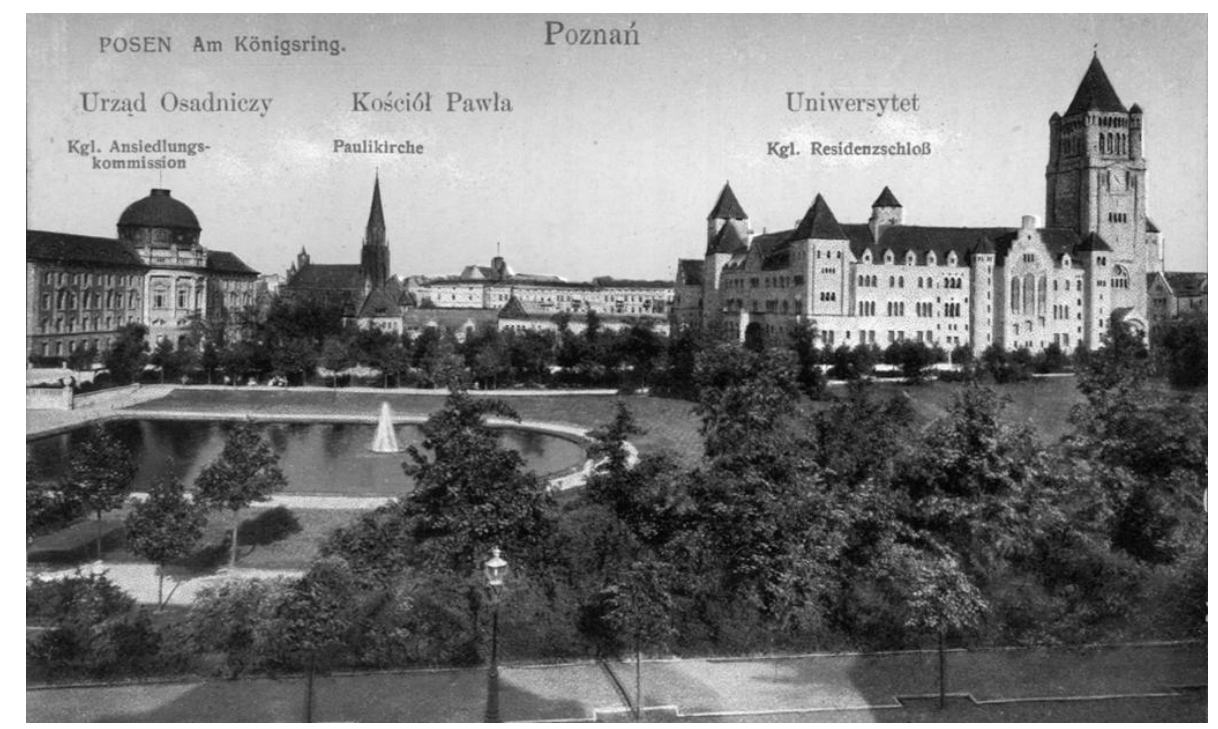

2. Posen, Schlossviertel. Gesamtansicht. Postkarte nach 1920. Biblioteka Uniwersytecka, Poznań

Eine Analyse der Situierung der Gebäude, ihrer Architektur und Funktionen sowie ihr Bezug zu polnischen und deutschen Investoren ergibt jedoch ein ganz anderes Bild der Aneignung und Inbesitznahme des städtischen Raums. Im Laufe des 19. Jahrhundts bildete hier fast jedes Gebäude einen Bestandteil der Identitätspolitik und des deutschpolnischen Nationalkonflikts, ein Gebäude stellte damals eine Antwort auf die Entstehung eines anderen dar, so dass man von einem Legitimationsduell sprechen kann. Die Architektur des Posener Wilhelmsplatzes als ein Teil der mitteleuropäischen Kulturraums gesehen, gehört zu den interessantesten Beispielen der „politischen Stadträume”. Es wäre vor allem mit der in den 1860er Jahren angelegten neuen Ringanlage in Brünn zu vergleichen, an der österreichische Regierungsbauten mit tschechischen und deutschen öffentlichen Gebäuden konkurrierten ${ }^{10}$.

10 M. Marek, „Monumentalbauten” und Städtebau als Spiegel des gesellschaftlichen Wandels in der 2. Hälfte des 19. Jahrhunderts. Die Landeshauptstädte in der Ära des bür- 
Die sich am Wilhelmsplatz vollziehende Bautätigkeit ging mit der Militarisierung und Germanisierung der Stadt einher. Sie fand unter anderem ihren Ausdruck in der Errichtung mehrerer Militärobjekte am Rande der Altstadt, die an exponierten Stellen als Dominanten oder „point de vue” in den nächsten Dezennien die städtebaulichen Achsen krönten. Zu den wichtigsten Objekten gehörte jedoch die über der Stadt emporragenden Zitadelle und der neue Festungsgürtel, der die Innenstadt dicht umfasste (1839). Damit wurde die frühere großzügige Aufklärungsidee der offenen Stadt annulliert. Im Jahre 1817 schrieb der Kommandant der Stadt Posen (Grollmann): „Posen muss eine Festung werden. Sie wird ein beredtes Zeugnis dafür sein, dass Preußen diesen Boden nie preisgeben wird und bereit ist, jegliche verschwörerischen Aktivitäten der Polen mit einem Schlag zunichte zu machen."11 Dies bildete das Leitmotiv für die hundertjährige polnische und deutsche Bautätigkeit in Posen sein, zugleich aber für die Polonisierung bzw. Repolonisierung der Stadt nach dem Ersten Weltkrieg ${ }^{12}$.

Lediglich der im Besitz der katholischen Kirche befindliche Grund und Boden unterlag nur in begrenztem Maße staatlicher Kontrolle und bot Möglichkeiten für ein relativ unbeschränktes Eintreten für das Polentum. Durch eine schleichende Säkularisation der Klöster, die nicht schlagartig wie in Preußen 1810 durchgeführt, sondern Schritt für Schritt noch nach 1793 und danach ab 1815 realisiert wurde, verlor die katholische Kirche im Großherzogtum Posen ihren Grundbesitz und Vermögen. Desto wichtiger war für die Bewahrung des nationalen Gedächtnisses die Dominsel in Posen, die nicht nur den Sitz des Bischofs beherbergte. Im polnischen Geschichtsbewusstsein wurde dieser Ort als Wiege des Christentums und des polnischen Staates verehrt. Er gehörte zu den wichtigsten symbolischen Orten, die man mit der Aufrechterhaltung der nationalen Identität und der Traditionskontinuität der polnischen Staatsidee assoziierte. Durch den Fluss Warthe von der Stadt abgesondert, bildete sie eine imaginierte Bastion des Polentums und der katholischen Kirche. Der damalige Bischof und Eduard Raczyński initiierten 1815 das Projekt zur Errichtung ein Mausoleum der ersten polnischen Herrscher der Piastendynastie in der Nähe des Domes ${ }^{13}$. Das Kon-

gerlichen Aufschwungs. Brünn: die Ringstrasse als Privileg und Attribut der Großstadt, (in:) Herausgegeben von Ferdinand Seibt im Auftrag des Adalbert Stifter Vereins München, Böhmen im 19. Jahrhundert. Vom Klassizismus zur Moderne, München, Frankfurt am Main, Berlin 1995, S. 149-163.

11 M. Rezler, Polityczna geneza pruskich fortyfikacji $w$ Poznaniu 1793-1828, (in:) B. Polak (Hg.), Poznańskie fortyfikacje, Poznań 1988, S. 65-83, insbes. S. 75.

12 A. Moskal, Im Spannungsfeld von Region und Nation. Die Polonisierung der Stadt Posen nach 1918 und 1945, Wiesbaden 2013.

${ }^{13}$ Grundlegend dazu: Z. Ostrowska-Kębłowska, Kaplica królów polskich, Poznań 1997. 
zept, ein freistehendes Denkmal auf dem Domplatz zu errichten, fand jedoch keine Anerkennung bei der damaligen Regierung. Deshalb entstand diese Gedenkstätte in der Kathedrale, wo die ehemalige, den Chorraum dominierende Marienkappelle für die neue Funktion umgebaut wurde. Die architektonischen und stilistischen Formen des Mausoleums, gedacht als ein Nationaldenkmal, knüpften an die byzantinische Baukunst an und sollten bildlich ,an die ruhmreichen Zeiten aus der polnischen Geschichte" erinnern (Franciszek Maria Lanci, 1835-1841). Das Geld für dieses Vorhaben wurde in den drei Teilungsgebieten gesammelt und das Bauunternehmen wurde somit zu einem Versuch, das polnische Volk symbolisch zu vereinen.

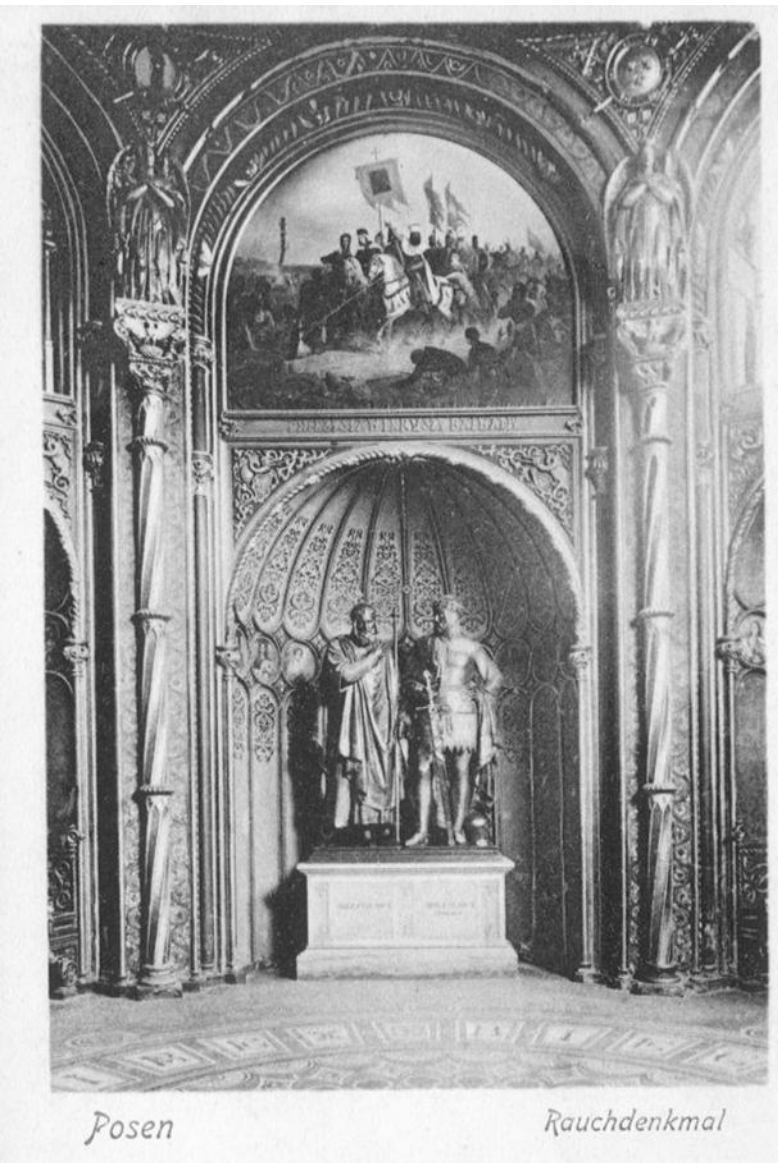

Dr. Trenkler \& Co., Leipzig. 1176
3. Posen, Mausoleum der ersten polnischen Könige im Dom. Postkarte vor 1914. Biblioteka Uniwersytecka Poznań 
In der ersten Hälfte des 19. Jahrhunderts entwickelten sich also in Posen zwei Grundzonen: die Dominsel, die als „eine feste Burg” des Polentums galt, und der neue Stadtteil, der zur Schaubühne der Nationalkonflikte, des deutsch-polnischen Wettkampfs und der fortschreitenden Germanisierung des öffentlichen Raums wurde. Beide trennte voreinander die Altstadt, eine Kontaktzone, die durch ihren polnisch-jüdischen Mischcharakter gekennzeichnet war. Und das Ganze wurde von der preußischen Zitadelle überragt.

Als ca. ein Jahrhundert später die Altstadt und die Gegend um den Wilhelmsplatz zum Zentrum der Stadt geworden waren, wurden außerhalb der - inzwischen erneut zur Festung umgestalteten - Stadt neue Wohngebiete angelegt, die im Stile der Reformarchitektur Berliner Prägung errichtet worden waren. Zugleich wurde nach den Plänen des damals besten deutschen Städteplaners Hermann Josef Stübben die Villensiedlung Solatsch (Sołacz) gebaut, die hauptsächlich von Deutschen und Juden bewohnt war. Um 1900 war die Stadt Posen in mehrere Zonen zerlegt, die ethnisch definiert wurden, was auch das architektonische, städtebauliche und stilistische Bild dieser Gegenden prägte. In dieser Zeit war Posen für die deutschen Beamten und Militärs, die aus dem Reich kamen, keineswegs attraktiv; vielmehr bedeutete, in Posen bleiben zu müssen, eine „Strafversetzung nach preußisch Sibirien”14. Nach und nach setzte sich die Ansicht durch, dass nur eine gründliche Modernisierung der Stadt der Ostflucht ein Ende setzen konnte. Der große Umbau der Stadt, unternommen im Rahmen des Programms „Hebung der Ostprovinzen", hatte abermals, wie hundert Jahre zuvor, einen zivilisatorischen Anspruch. Auf dem ehemaligen Festungsgelände entstand nach den Plänen von H.J. Stübben das sogenannte Schlossviertel, das man als das letzte Kaiserforum Europas bezeichnen kann (errichtet zwischen 1904-1910, nach den Plänen von mehreren führenden deutschen Architekten) ${ }^{15}$. Auf dem frei gewordenen Gelände der alten Festung sollten die repräsentativsten, darunter auch öffentlichen Gebäude errichtet werden. Dieses umfangreiche Projekt wurde fast ausschließlich aus der Staatskasse finanziert und hauptsächlich von Berliner Architekten umgesetzt. In der Stilistik der Bauten überwogen neuromanische und neubarocke Formen, die damals als deutscher Nationalstil galten. Zur neuen Anlage

14 Ch. Myschor, Wyżsi urzędnicy pruskiej administracji prowincjonalnej w Poznańskiem (1871-1918), Poznań 2014; idem, Dienen in „Preußisch Sibirien”. Zur sozialen Stellung, Funktion und Kontakten der höheren Beamten in der Provinz Posen 1871-1918, „Jahrbuch des Bundesinstitutes für Kultur und Geschichte der Deutschen in östlichen Europa“, Jg. 21 (2013), S. 243-268.

15 Grundlegend dazu: Z. Pałat, Architektura a polityka. Gloryfikacja Prus i niemieckiej misji cywilizacyjnej w Poznaniu na początku XX wieku, Poznań 2011. 
zählten insgesamt vierzehn Gebäude, die verschiedene Behörden sowie staatliche, wissenschaftliche und kulturelle Einrichtungen beherbergten (kaiserliche Residenz, Königliche Akademie, deutsches Theater, Ansiedlungskommission, sowie Kreditinstitute für deutsche Ansiedler, Hauptpost und das evangelische Vereinshaus - quasi ein Deutsches Haus und die früher erbaute ev. Kirche von F.A. Stüler). Die politische und architektonische Dominante bildete die neue Kaiserresidenz, die als eine mächtige, neoromanische Burg von wehranmutendem Charakter konzipiert und am Hauptzufahrtsweg zur Stadt vom Westen und vom Hauptbahnhof situiert war ${ }^{16}$. Ihr Entwurf stammte von Franz Schwechten, dem Spitzenarchitekten des Kaiserhofes. Die üppige Ausgestaltung der Innenräume betonte die Legitimität der Hohenzollern-Herrschaft und des „Drangs nach Osten” in der Provinz Posen und stellte Wilhelm II. als Nachfolger der Karolinger und Fortführer des Heiligen Römischen Reichs Deutscher Nation dar. Von besonderer Bedeutung war die Schlosskapelle, deren Stil die gleiche byzantinische Prägung aufwies wie das 70 Jahre zuvor eingerichtete Mausoleum der polnischen Könige im Posener Dom. Beide Kapellen wetteiferten bei der Vermittlung nationaler und patriotischer Inhalte miteinander und hatten die Aufgabe, den jeweiligen nationalen Anspruch auf das Posener Gebiet zu legitimieren.

Die Bauten des Schlossviertels sollten die Legitimierung der kaiserlichen Hoheit bezeugen, die Kolonisation dieser Gebiete durch die Deutschen würdigen, die Bedeutung der deutschen Wissenschaft und Kunst für die Bildung der nationalen Identität und die Verdienste um die Entwicklung der Provinz hervorheben sowie die deutsche Bevölkerung dazu ermuntern, die Randgebiete des Staates statt zu verlassen eher zu besiedeln mit dem Auftrag, so einer historischen Verpflichtung gerecht zu werden. Zur Anlage sind noch die königliche Kaiser-Wilhelm I.-Bibliothek und das Kaiser-Friedrich III.-Provinzialmuseum zu zählen, die sich in der Nähe des Wilhelmsplatzes befanden. Das Bismarckdenkmal und das Kaiser Friedrichdenkmal vereinigten symbolisch die zwei wichtigsten Posener Plätze als Orte deutscher Identität. So wurde die Posener City mit Institutionen punktuell markiert, die neue Identifikationsräume einer für Polen fremden Prägung bildeten und ein Zeugnis der deutschen kulturellen und staatspolitischen Dominanz darstellten. Die feierliche Eröffnung des Schlosses 1910 in Anwesenheit des Kaisers wurde von Polen und der polnischen Presse fast vollständig ignoriert ${ }^{17}$.

16 J. Pazder, E. Zimmermann (Hg.), Kaiserschloss Posen. Zamek cesarski w Poznaniu. Von der „Zwingerburg im Osten” zum Kulturzentrum „Zamek”. Od pruskiej „warowni na wschodzie” do Centrum Kultury „Zamek”. Potsdam-Poznań 2003.

${ }_{17} \mathrm{Ch}$. Myschor, Dni Cesarskie w Poznaniu. Różne aspekty uroczystych wizyt Wilhelma II $w$ mieście w latach 1902-1913, Poznań 2010, S. 190-193. 
Posen zählte vor dem Ersten Weltkrieg sicherlich zu den interessantesten mitteleuropäischen Städten, in der konkurrierende politische und gesellschaftliche Kräfte miteinander um die Aneignung des städtischen Raums und die nationale Markierung zentraler Orte sowie Wohnanlagen wetteiferten. Das neue Schlossviertel in Posen lässt sich vor allem mit der Neustadt von Straßburg vergleichen, wo eine ähnlich repräsentative und nationalgeprägte städtebauliche Anlage zwischen der neugegründeten deutschen Universität und der Kaiserresidenz nach 1871 realisiert wurde ${ }^{18}$. Beide Anlagen, in Straßburg und Posen, waren Zeugnisse der Inbesitznahme eines mehr (Provinz Posen) oder weniger (Reichsland Elsass und Lothringen) fremden Territoriums, in dem Architektur und Städtebau eine führende visuelle Rolle im Prozess der inneren Kolonisation spielten.

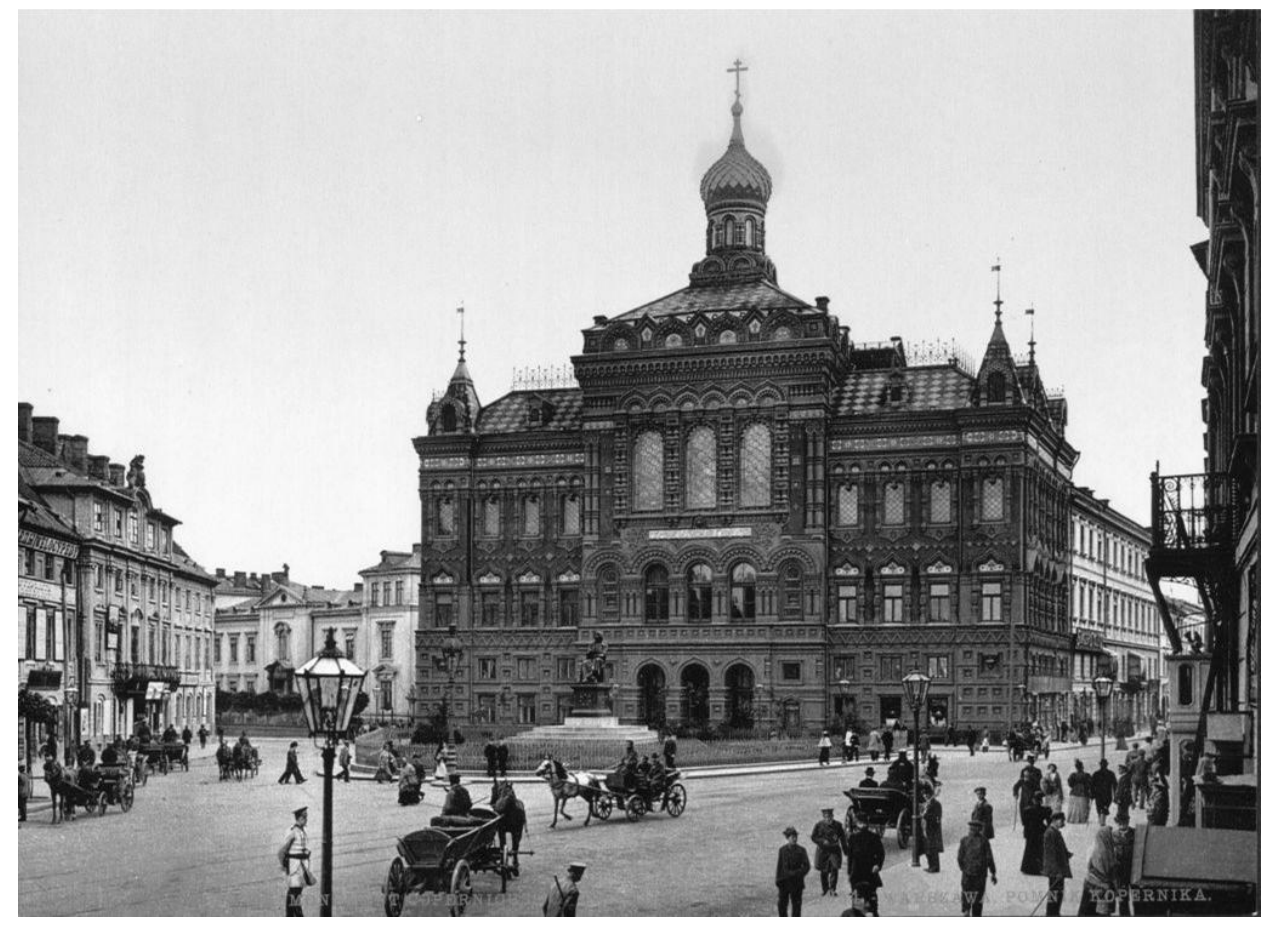

4. Warschau, Staszic Palais nach dem Umbau. Postkarte vor 1915, http://hdl.loc.gov/ loc.pnp/ppmsc.03919

18 K. Nohlen, Baupolitik im Reichsland Elsaß-Lothringen 1871-1918. Die repräsentativen Staatsbauten um den ehemaligen Kaiserplatz in Straßburg, Berlin 1982 (Kunst, Kultur und Politik im Deutschen Kaiserreich, Vol. 5). 
$\mathrm{Zu}$ den interessantesten politisch und national überlagerten Stadträumen im geteilten Polen gehörte auch Warschau, das 1815-1831 Hauptstadt des Königreichs Polen war, des Staates, der durch Personalunion mit dem russischen Zarenreich verbunden war. Nach dem Novemberaufstand 1830/31 verlor das Königreich Polen seine Autonomie und wurde Schritt für Schritt in das russische Reich politisch und wirtschaftlich eingebunden, was aber dessen schnelle demographische und industrielle Entwicklung nicht verhinderte.

Die Warschauer Raumgestaltung stellte in Mitteleuropa einen Sonderfall dar: das kleine Altstadtgebiet hatte im 19. Jahrhundert keine Bedeutung mehr, die Stadt hatte auch keine großen Befestigungsanlagen, so dass es zu spektakulären Entfestigung oder Anlegung breiter Promenaden keinen Anlass gab ${ }^{19}$. Der Schauplatz der baulichen Initiativen war die Hauptstraße (Krakowskie Przedmieście), eine Via Regia, die vom königlichen Schloss zu den königlichen Residenzanlagen (Ujazdów, Łazienki, Wilanów) und weiter nach Krakau führte. Die barocken und klassizistischen Adelspaläste, die früher Schauplatz des höfischen Lebens waren, änderten ihren Charakter nach der letzten Teilung Polens: teilweise wurden sie in Beschlag genommen und für Zwecke staatlicher Behörden umfunktioniert. Somit wurde die Straße zum Amtszentrum der Hauptstadt, obwohl ihre Architektur unverändert blieb. Nach 1815, also in der Zeit der relativen Autonomie des Königreichs Polen, wurde diese neue funktionelle Straßenstruktur um wichtige Bauten erweitert. Die Gebäude der neugegründeten Universität und der benachbarte prächtige Sitz der Gesellschaft der Freunde der Wissenschaften (Staszic Palais) mit dem Copernicus-Denkmal - entstanden aufgrund von Initiativen der polnischen intellektuellen Elite und dank der Zustimmung des polenfreundlichen Zaren Aleksander I. Auch an anderen Stellen wurden intensive Modernisierungsarbeiten durchgeführt (neue Regierungssitze, eine Bank, modernes Stadttheater, Platzanlagen), so dass Warschau um 1830 auf Grund der Zahl und Größe der repräsentativen öffentlichen Gebäuden und modernen Stadtanlagen mit anderen mitteleuropäischen Metropolen wetteifern konnte. Die Situation änderte sich mit der Niederlage des Novemberaufstandes (1830-1832) und besonders nach der zweiten verloren Erhebung (Januaraufstand) 1863-1864. Die Russifizierungspolitik sowie die nationalen Konflikte nahmen an Intensität zu. Viele Einrichtungen und Vereine des oktroyierten polnischen Staatswe-

19 E. Szwankowski, Warszawa. Rozwój urbanistyczny $i$ architektoniczny, Warszawa 1952, S. 155-268 (schon veraltet, aber noch immer grundlegend); A. Łupienko, Przestrzeń publiczna Warszawy w pierwszej połowie XIX wieku, Warszawa 2012, S. 78-157. 
sens wurden abgeschafft und zahlreiche Paläste erneut in Beschlag genommen. Zur gleichen Zeit wie in Posen (also in den 30er Jahre des 19. Jahrhunderts) wurde eine mächtige Zitadelle mit einem Gefängnis errichtet und die Stadt von einem Ring aus Kasernen, Exerzierplätzen und einem Fortsystem umfasst, der Eingemeindungen und Erweiterungen der Stadt bis 1915 verhinderte. Systematisch verschwanden polnische Klöster, die säkularisiert wurden, und katholische Kirchen wurden in orthodoxe Gotteshäuser umgewandelt ${ }^{20}$. An der Wende vom 19. zum 20. Jh. nahmen die nationalen Konflikte zu. Diese Spannungen hatten unter anderem eine Intensivierung der politischen Baumaßnahmen zur Folge, die in den ersten Jahren des 20. Jahrhunderts ihren Höhepunkt erreichten.

Die Präsenz der russischen Macht war in Warschau durch keine prachtvolle Zarenresidenz, obwohl eine solche entworfen worden war ${ }^{21}$, sichtbar. Es gab auch keine „russischen Reviere”22 und keine separierten, nur für die russische Bevölkerung bestimmten Gebäude, die mit der hohen Kultur zusammenhingen (das Theater verbunden mit der Bibliothek, mit dem Lesesaal und dem Festsaal, war zwar 1905 geplant, aber nicht realisiert wurde ${ }^{23}$ ). Trotz dieser Unzulänglichkeiten gehörte Warschau neben Petersburg zu den Zentren des russischen Imperium, die einen deutlich ausgeprägten europäischen Charakter besaßen, und unter Russen galt die Stadt als ein attraktiver Wohn- und Karriereort, der von ihnen sogar „Paris des Ostens” genannt wurde (also völlig anders als Posen - „Preußisch Sibirien” genannt) 24.

${ }^{20}$ P. Paszkiewicz, Pod bertem Romanowów. Sztuka rosyjska w Warszawie 1815-1915, Warszawa 1991, S. 55-66; P.P. Gach, Kasaty zakonów na ziemiach dawnej Rzeczypospolitej $i$ Śląska 1773-1914, insbes. S. 87-115, 175-192, Lublin 1984; C. Jastrzębski, Kasaty klasztorów w Królestwie Polskim w 1864 r., (in:) Kasaty klasztorów na obszarze dawnej Rzeczypospolitej Obojga Narodów i na Ślasku na tle procesów sekularyzacyjnych w Europie, Bd. 1 Geneza. Kasaty na ziemiach zaborów austriackiego i rosyjskiego, M. Derwich (Hg.), Wrocław 2014, S. 249-367, insbes. S. 364-365.

21 A. Idźkowski, Plany budowli obejmujące rozmaite rodzaje domów, mieszkań wiejskich różnej wielkości, kościołów, gmachów publicznych, mostów, ogrodów, monumentów itp. Szczegótów $w$ rozmaitych stylach architektury przez (...) Budowniczego Rzadowego, członka Akademii Florenckiej Sztuk Pięknych, Warszawa 1843, S. 18, Tafel CX, CXIVCXX, op. cit., S. 79-80; T. Jaroszewski, O siedzibach neogotyckich $w$ Polsce, Warszawa 1981, S. 82-85.

22 Die russischen Eliten bevorzugten die schönste Wohngegend Warschaus um Łazienki Park und Aleje Ujazdowskie (Ujazdowskie Alleen), wo sich die Zarenresidenz in Łazienki, Kaserne, Militärhospital, Kadettenschule, sowie repräsentative russisch-orthodoxe Erzengel Michael-Kirche (1897) etc. befanden.

${ }^{23}$ M. Rolf, op. cit., S. 207-208.

${ }^{24}$ Zur Auseinandersetzung mit dem Begriff „Warschau als Paris des Ostens”; B. Brzostek, Paryże Innej Europy. Warszawa i Bukareszt, XIX i XX wiek, Warszawa 2015. 


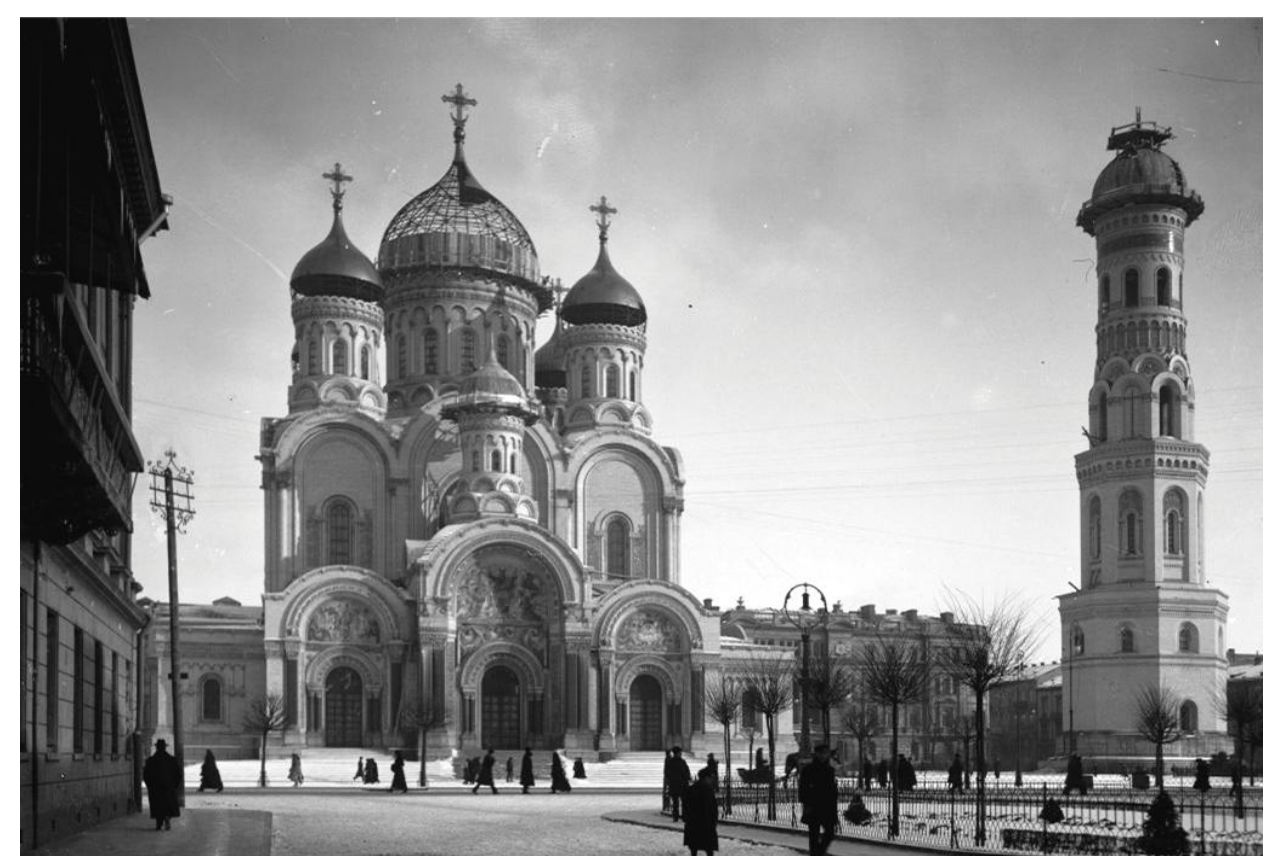

5. Warschau, Orthodoxe Nevskij Kathedrale auf dem Saski-Platz. Foto 1917. Fotosammlung Instytut Sztuki, Polska Akademia Nauk, Warszawa

Die „Okzidentalisierung” des Antlitzes Warschaus ging mit der gleichzeitigen Russifizierung einher - beide haben brillante Architekturbeispiele hinterlassen ${ }^{25}$. Eine der drastischsten politischen Umbaumaßnahmen im Rahmen der Russifizierungspolitik war die Umwandlung des ehemaligen klassizistischen Sitzes der Gesellschaft der Freunde der Wissenschaften (Staszic Palais)- eines Symbols des Polentums - in ein russisches Gymnasium mit orthodoxer Kirche (Entwurf Władimir Pokrowski, 1895)26. Die neue Fassade erhielt dabei eine russisch- byzantinische Stilisierung. Der russische Charakter der Gegend wurde zusätzlich durch die in der Nähe errichtete orthodoxe Kathedrale unterstrichen ${ }^{27}$. Es war

${ }^{25}$ Grundlegend: P. Paszkiewicz, op.cit.; M. Rolf, op.cit., S. 283-324, insbes. S. 303-313.

26 Paszkiewicz, op.cit., S. 95-103.

27 Idem, S. 114-137. Idem, The Russian Orthodox Cathedral of Saint Alexander Nevsky in Warsaw. From the History of Polish - Russian Relations, „Polish Art Studies”, Bd. 14 (1992), S. 63-72. M. Rolf, Russische Herrschaft in Warschau. Die Aleksander Nevskij-Kathedrale im Konfliktraum politischer Kommunikation, (in:) W. Sperling (Hg.), Jenseits der Zarenmacht. Dimensionen des Politischen im Russischen Reich 1800-1917, Frankfurt/New York 2008, s. 163-190. Zur Bedeutung des Patroziniums Aleksander Nevskij im 19. Jahrhundert siehe: F.B. Schenk, Aleksander Nevskij. Heiliger - Fürst - Nationalheld. Eine Erinnerungsfigur im russischen kulturellen Gedächtnis (1263-2000), Köln, Weimar, Wien 2004, S. 168-225. 
das prominenteste russische Bauprojekt im Polnischen Teilungsgebiet, das, aus Spenden des ganzen (russischen Volkes) finanziert, vom Zaren großzügig unterstützt wurde und bezeichnenderweise den Namen von Alexander Nevskij trug (1894-1912). Dieses Gotteshaus, entworfen von Leontij Benois - einem der bedeutendsten russischen Architekten, wurde an einem der Zentralplätze Warschaus errichtet (Saski Platz). Es war gut sichtbar von der Hauptstrasse - Krakowskie Przedmieście, hatte den höchsten Turm in Warschau und ragte über die öffentliche Hauptgrünanlage und benachbarten Häuser empor. Seine Stilistik knüpfte absichtlich an die hervorragendsten Sakralbauten des russischen Imperiums an. Die Nevskij-Kathedrale, das umgebaute Staszic Palais und die ehemalige polnische Universität, umgewandelt in eine russische Universität, standen dicht beieinander und bildeten somit am Ende des 19. Jahrhunderts, zusammen mit den anderen staatlichen- und Militärinstitutionen, einen neuen Kristallisationspunkt russischer Macht und politischer Demonstration im Zentrum Warschaus. Diese Gegend, noch in der ersten Hälfte des 19. Jahrhunderts polnisch kodiert, hatte ein halbes Jahrhundert später seine politische Aussage grundsätzlich geändert.

Auf diese russischen Investitionen reagierten polnische Kreise. Ein Paradebeispiel dafür ist die Entstehung des Polytechnischen Instituts in Warschau. Der Gründungsprozess war mit der s.g. „Neuen Ära” verbunden, die mit der Thronbesteigung Nicolaus II 1894 begann. Anlässlich seiner ersten Polenreise 189728 hatte der Zar den Wunsch geäußert, statt Geschenken Gelder für eine noch nicht bestimmte Wohltätigkeitsinstitution zu sammeln ${ }^{29}$. Das Komitee, das die Sammlung organisierte, nahm dies zum Anlass, den Zaren um die Genehmigung zur Errichtung einer Polytechnischen Hochschule in Warschau zu bitten. Es war sicher im Interesse der vorwiegend polnisch-jüdischen Wirtschaftskreise, den Nachholbedarf an technischem Wissen an Ort und Stelle zu beseitigen. Die schnell fortschreitende Industrialisierung von Warschau und Umgebung schuf eine wachsende Nachfrage nach Technikern und Ingenieuren, für deren Ausbildung keine geeignete Institution zur Verfügung stand. Die technische Presse beklagte, dass die Jugendlichen an deutschen Hoch-

${ }_{28}$ M. Rolf, Der Zar an der Weichsel: Repräsentationen von Herrschaft und Imperium im fin de siècle, (in:) J. Baberowski, D. Feest, Ch. Gumb, (Hg.), Imperiale Herrschaft in der Provinz. Repräsentationen politischer Macht im späten Zarenreich, Frankfurt a.M., New York 2008, S. 145-171.

29 J. Sobczak, Polskie fascynacje młodym cesarzem Mikołajem II: geneza jego wizyty warszawskiej we wrześniu 1897 i próba polsko-rosyjskiej „ugody”, „Mazowieckie Studia Humanistyczne” Bd. 2, Nr 1, (1996), S. 5-39, insbes. S. 34-36. 
schulen studierten und nicht zurückkehrten ${ }^{30}$. Die russischen Oberbehörden, vor allem der relativ polenfreundliche Generalgouverneur Alexander Imeretinski stimmten dem Vorschlag zu unter der Voraussetzung, dass die hierfür noch benötigten Gelder ebenfalls von polnischer Seite aufgebracht würden ${ }^{31}$. Die von jüdischen Industriellen und Bankiers sowie polnischen Adeligen, die in der Wirtschaft engagiert waren, gesammelte Summe (3,5 Millionen Rubel) machte es möglich, dass bereits 1901 die moderne Campusanlage am Rande der City eröffnet werden konnte $^{32}$.

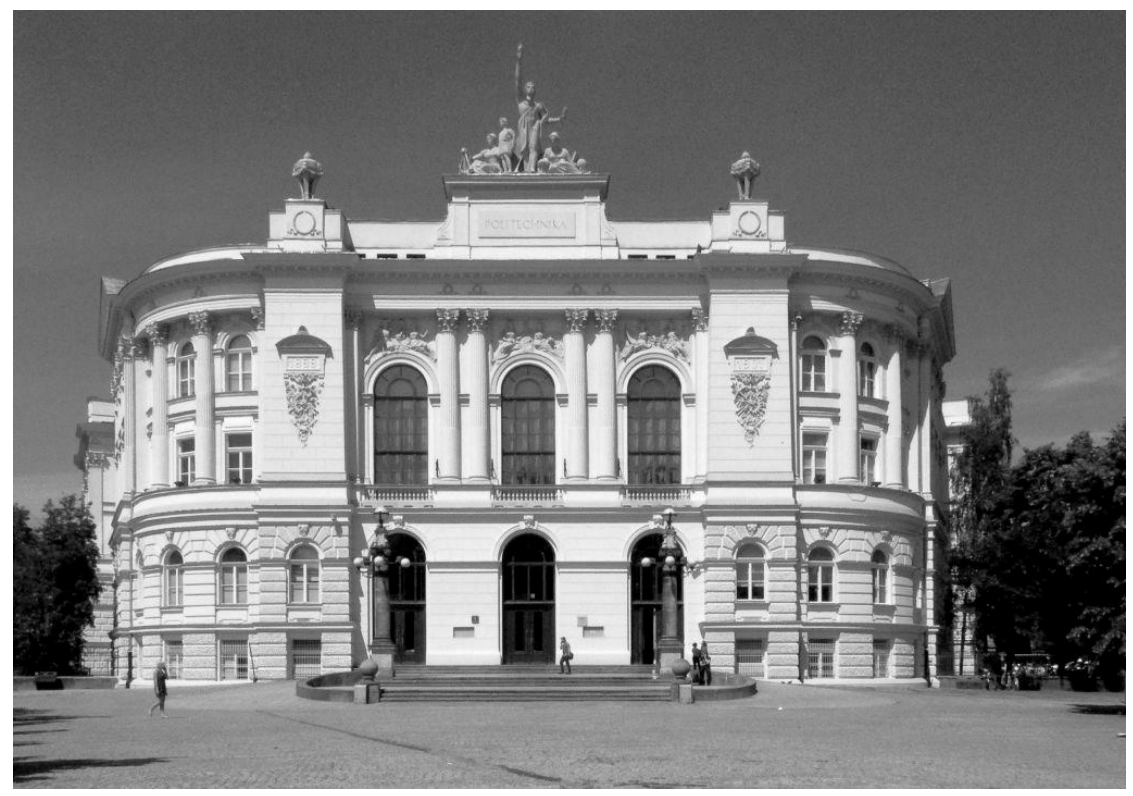

6. Warschau, Polytechnisches Nicolaiinstitut. Foto 2016, Fot. A. Zabłocka-Kos

„Wer die Schule hat, hat das Land” - dieser deutsche Spruch, der im Zusammenhang mit der Gründung der Universität in Straßburg nach

30 M. Baraniecki, Uwagi o urządzeniu u nas Szkoly Wyższej Technicznej, „Ateneum”, Bd. 3, Heft 9 (1880), S. 516-534, insbes, 523f. http://buwcd.buw.uw.edu.pl/e_zbiory/ckcp/ ateneum/1880/zeszyt09/imagepages/image111.htm (dostęp 20.10.2015); Vgl. auch E. Domański (Hg.), 150 lat wyższego szkolnictwa technicznego $w$ Warszawie 1826-1976, Warszawa 1979.

31 Tajne dokumenty rządu rosyjskiego w sprawach polskich, Wyd. 2. Memoryał ks. Imeretyńskiego, Protokóły Komitetu Ministrów, Nota Kancelaryi Komitetu Ministrów. London 1899, S. 34-37 In: archive.org/stream/tajnedokumentyr00unkngoog\#page/n3/mode /2up, (20.10.2015), S. 34-37, 77.

32 J. Piłatowicz, Ruch stowarzyszeniowy inżynierów i techników polskich, t. 1, Warszawa 2003, S. 156. 
der Annexion des Elsass geäußert wurde ${ }^{33}$, klang in Warschau besonders ominös. Die Errichtung des Polytechnischen Instituts ist als ein Kompromiss und eine Ausbalancierung verschiedener Interessen zwischen fremden und einheimischen Kräften zu verstehen. Das von Polen gesammelte „Geldgnadengeschenk” sollte den Zaren zur Milderung der massiven Russifizierungspolitik und zu einer gewissen Versöhnung bewegen. Der gemischt russisch-polnische Magistrat war sich sehr schnell einig, kostenlos ein großes Grundstück zur Verfügung zu stellen. Das Baukomitee, bestehend aus reichen Warschauer Bankiers und Industriellen (meistens jüdischer Abstammung), konnte selbst entscheiden, wer das Projekt anfertigen und welche Form und Stilistik die ganze Anlage tragen sollte. So ist festzustellen, dass trotz der Unterdrückung und Begrenzung der polnischen Initiativen ausgerechnet die Gründung und Errichtung der technischen Hochschule (Polytechnisches Nikolaiinstitut) in Warschau, finanziert von Polen, aber als russische Lehranstalt gedacht, beiden Seiten diente. Der Lehrkörper des neuen Institutes bestand vornehmlich aus Russen und die Lehrsprache war russisch, dagegen aber waren die Studenten zu 70\% polnisch.

$\mathrm{Zu}$ dieser Zeit befand sich in Warschau die bereits erwähnte, überdimensional große Nevskij Kathedrale im Bau, die dem Bedürfnis nach staatlichen Repräsentationsbauten im russischen Stil und der Machtausübung Rechnung trug. Das Polytechnikum stellte ein Pendant dazu dar. Zwei der besten Warschauer Architekten Stefan Szyller und Bronisław Rogóyski, gewählt vom Komitee, schufen die Pläne, die sich an repräsentativen europäischen Hochschullösungen orientierten und mit ihrer neutralen Neorenessaincestilistik nicht den Verdacht erregten, sie seien polnisch gefärbt. In den Außenformen festlich, fast theatralisch geplant (auffallende Ähnlichkeiten mit dem Hofburgtheater in Wien), im Inneren jedoch an einen der schönsten polnischen Renaissancepaläste anknüpfend gehörte das Polytechnische Nicolaiinstitut zu den prächtigsten Bauten seiner Zeit in Warschau. In den Augen der russischen Administration hatte es die Aufgabe, eine Modelleinrichtung in den westlichen Teilen des Imperiums darzustellen und gleichzeitig als ein Kristallisationspunkt die städtebauliche Entwicklung des Randgebietes der Hauptstadt zu beschleunigen ${ }^{34}$. Die Hauptakteure dieses Unternehmens waren

${ }^{33}$ H. Hammer-Schenk, "Wer die Schule hat, hat das Land”. Gründung und Ausbau der Universität Straßburg nach 1870, (in:) E. Mai, S. Waetzlodt (Hg.), Kunstverwaltung Bau- und Denkmal-Politik im Kaiserreich, Berlin 1981 (Kunst, Kultur und Politik im Deutschen Kaiserreich, Bd 1), S. 121-145, insbes. S. 125.

34 A.A. Wagner, Architecture of the Warsaw University of Technology, Warszawa 2001, S. 11-92. M. Omilanowska, Architekt Stefan Szyller 1857-1933, Warszawa 2008, S. 46, 132, 
Polen, die Entscheidungen aber wurden in Petersburg in den Ministerien, am Zarenhof und im Generalgouvernementamt sowie im Magistrat in Warschau getroffen. Ohne die Initiative „von unten” jedoch wäre diese Institution nicht entstanden.

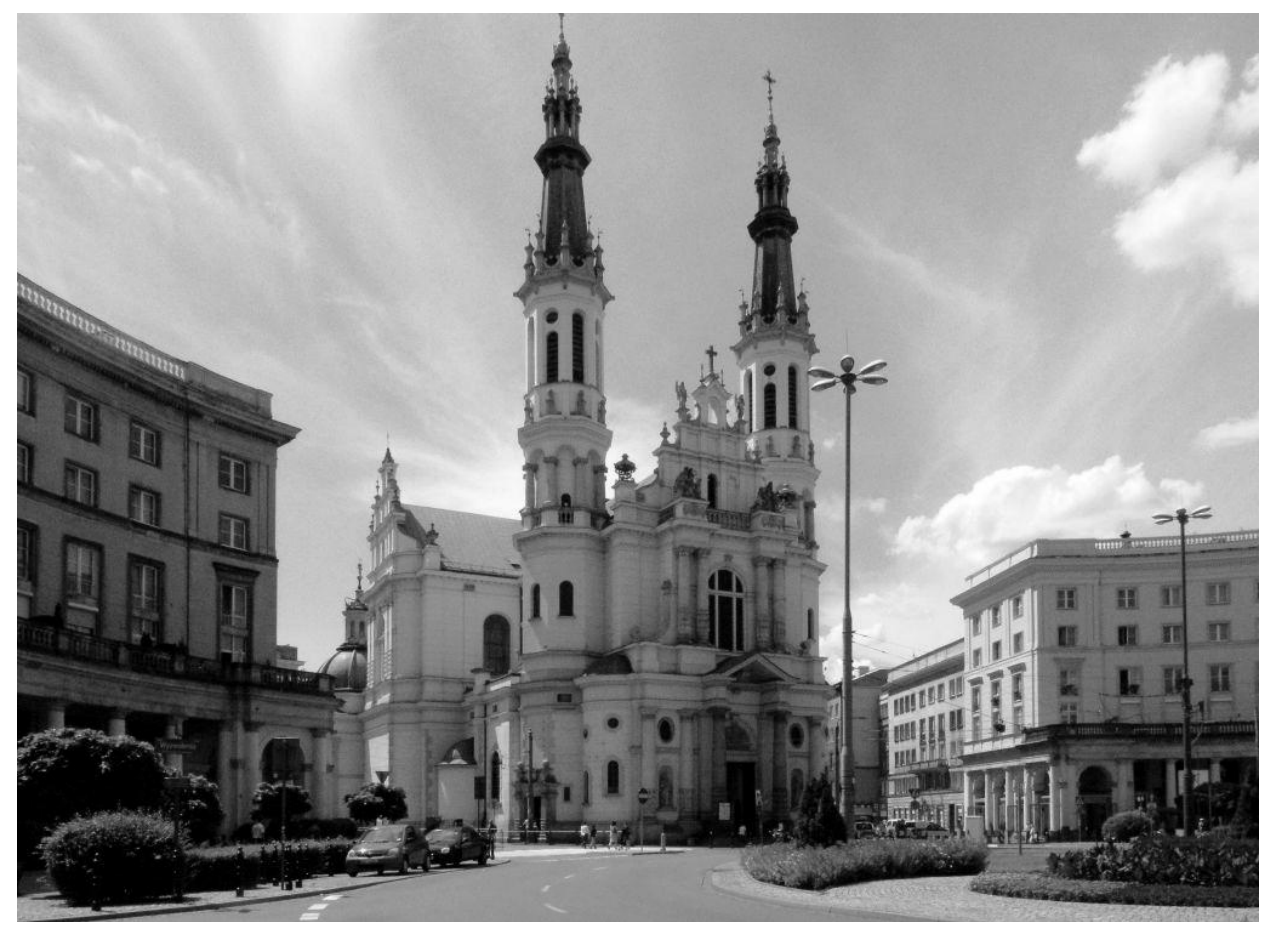

7. Warschau, Erlöserkirche. Foto 2016, Fot. A. Zabłocka-Kos

Auf diese gemischte Investition reagierten polnische, patriotisch gesinnte Kreise mit dem Bau einer katholischen Kirche in unmittelbarer Nähe des Polytechnikums. Ähnlich wie im Fall der orthodoxen Gotteshäuser strebte man dabei an, sie am Platz zu situieren (plac Zbawiciela, Erlöserplatz), der die Straßenperspektive der Warschauer Haupteinkaufsstrasse Marszałkowska schliesst. Damit war der Bau von fern sichtbar. Die neue Erlöserkirche (kościół p.w. Najświętszego Zbawiciela, die Wahl des Patronsnamen war nicht zufällig), entworfen von einem polnischen Architekten, bekam - als national verstandene Krakauer Neorenaissance - Formen, die, im Gegensatz zur internationalen Neorenaissancestilistik des Polytechnikums, das authentische Polentum ver-

133, 138, 139, 263-270; T.S. Jaroszewski, A. Rottermund, „Renesans polski” $w$ architekturze XIX i XX w., (in:) Renesans. Sztuka i ideologia, Warszawa 1976, S. 618, 623. 
sinnbildlichen sollten ${ }^{35}$. Diese Kirche befand sich an der städtebaulichen Achse zwischen dem Polytechnischen Nicolaiinstitut und einer im russischen Stil erbauten russisch-orthodoxen Erzengel Michael-Kirche in der Nähe des Łazienki Parks. Die Erlöserkirche bildete auf dieser Achse einen Schlüsselpunkt und die höchste Dominante des neuen Teils der Warschauer City. Durch ihre Funktion, Situierung, Form, Stilistik, Namensgebung und die beteiligten Akteure kontextualisierte sie einen politisch-kirchlichen polnischen Patriotismus.

Die wichtigste Rolle in der Eroberung des städtischen Raums und in der Bildung der politisch-symbolischen Territorien spielte in Warschau die Sakralarchitektur - also der Bereich, in dem Polen ihre nationale Identität und Russen ihre Macht und Bindung der orthodoxen Kirche ans Zarentum ausdrückten.

Aber auch die Umbaupläne für Warschau, die in der Warschauer Presse publiziert wurden, sind ein interessanter Beitrag zum Thema Modernisierung der Metropole und zum Versuch der polnischen und russischen Eliten und Behörden, diese Stadt zu „europäisieren”. Im Revolutionsjahr 1906 veröffentlichte Antoni Lange, Schriftsteller, Poet und Philosoph jüdischer Abstammung, ein „futuristisches Projekt”, das das Bild von Warschau verändern sollte ${ }^{36}$. Er schlug vor, die wichtigsten symbolischen Orte der Stadt mit Kopien der national gefärbten Krakauer Bauten zu krönen. So sollte die verhasste Zitadelle verschwinden und der Hügel erhöht werden, so dass er über Warschau dominiert, und durch architektonische Kopien der Wawelburg und der Kathedrale ersetzt werden. Vor der Zarenresidenz (dem ehemaligen königlichen Schloss) sollten die russischen Kasernen beseitigt werden, und wieder aufgegriffen wurde die alte Idee, das Schloss mit dem Parlamentsgebäude „im ernsten griechischen Stil" mit Büsten der Staatsväter zu erweitern. Entlang der Weichsel sollte der ärmste Teil von Warschau - Powiśle - mit Boulevards und Grünanlagen verschönert werden. Lange plante dort neue Repräsentationsalleen und -plätze, die sich an Venedig und der Wiener Ringstrasse orientierten, mit zentralen öffentlichen Gebäude wie Atheneum, Bibliotheken, Museen (Uffizi), Akademie der Wissenschaften, Athletikon (Sportpalais) etc. bebaut. Denkmäler der Nationalhelden gehörten zu den wichtigsten Punkten der geplanten neuen Markierung des städtischen

${ }^{5}$ Dazu ausführlich: K. Stefański, Polska architektura sakralna $w$ poszukiwaniu stylu narodowego, Łódź 2002, S. 84-89. Der Wettbewerb ausgeschrieben 1900, der Bau, nach dem Plänen von Józef Pius Dziekoński, beendet 1903.

${ }^{36}$ Dazu ausführlich: B. Arciszewska, M. Górzyński, Urban Narratives in the Age of Revolutions: early 20th century Ideas to Modernize Warsaw, „Artium Quaestiones” XXVI, 2015, S. 101-147. 
Raums. Die „schlechte” Gegend, bewohnt von armen Polen und Juden, sollte durch eine moderne Bürgerstadt ersetzt werden, die deutlich eine Gegenöffentlichkeit zur „russischen Oberstadt” im ganzen städtischen Raum bildete, aber auch die weitere Gentrifizierung des städtischen Raums unterstrich. Langes Utopie war ein Versuch, den man im Zusammenhang mit den Bestrebungen der gemischten polnisch-jüdischen Warschauer Elite sehen muss, die Stadt nicht nur in ein „Paris des Ostens” im Sinne der amerikanischen „City Beautiful” Bewegung umzuwandeln, sondern unter nationalen und gesellschaftlichen Aspekt zu sanieren und zu teilen. Gleichzeitig sprach Lange im Namen des nicht existierenden Stadtrates, den es in Warschau nicht gab und nicht geben konnte.

Um 1900 sah man deutlich, wie schnell auf Grund der miserablen russischen Stadtpolitik Warschau sich, trotz des angeblichen „Pariser Hauchs", vom europäischen Niveau entfernte. Das Revolutionsjahr 1906 war eigentlich der einzig mögliche Zeitpunkt, die Diskussion über eine gründliche Modernisierung zu beginnen und einige frühere Ideen fortzusetzen in der Hoffnung, sie auch zu verwirklichen. Die nationale Ebene die Kopien des alten Krakaus - wurde in diesen Plänen mit der europäischen Ebene (Pariser Glanz der späthistorizistischen Gebäude) amalgamiert, um eine neue, spezifisch Warschauer Inszenierung der Modernität zu schaffen

Langes Plädoyer für eine Modernisierung des verfallenen und armen Stadteils entsprach sowohl den Wünschen von Hygienikern, die Elendsviertel zu sanieren, wie auch den Vorstellungen der Warschauer gemischten jüdisch-polnischen Bourgeoisie, ein stattliches Viertel in äußerst attraktiver Gegend zu schaffen. Es war auch mit dem generellen Trend verbunden, Kais und Ufer im städtischen Bereich zu regulieren und repräsentativ zu bebauen. $\mathrm{Zu}$ den besten Beispielen gehörten damals die neuen architektonischen Arrangements in Koblenz (Deutsches Eck), Dresden (Brühlsche Terrasse), Stettin (Hackenterasse) und besonders in Budapest (mit dem Parlament und Kaiserresidenz am Donauufer). Besondere Bedeutung könnte für Warschau auch die in den 90er Jahre des 19. Jahrhunderts begonnene Assanierung der jüdischen Josephstadt in Prag gehabt haben, die mit der neuen Bewertung und Bebauung der Moldauufer in Korrespondenz stand. Das reiche Großbürgertum sollte die arme jüdische Bevölkerung der Josephstadt ersetzten und prächtige Kollegiengebäude der beiden Prager (tschechischen und deutschen) Universitäten sollten als Hauptzierden des Ufers der Hauptstadt neuen 
Glanz verleihen ${ }^{37}$. Die vorbildlichen Stadträume am Fluss brachten in den Städten um 1900 nicht nur die Macht und das Mäzenatentum des Staates zum Ausdruck, sondern spiegelten auch, wie in Prag und Warschau, die Kräfte wider, die den nationalen Stolz mit der Stärke des Großbürgertums vereinigten und gleichzeitig zu sozialer Säuberung und Segregation führten. In Warschau blieb Langes Idee eine unverwirklichte Utopie, die erst hundert Jahre später eine partielle Realisierung fand.

Eine andere Entwicklung nahm die Aneignung des städtischen Raumes durch verschiede Kräfte in Krakau. Diese Stadt gehörte, in der kurzen Periode um 1800 und dann ab 1846 zu Österreich. Nach der ersten Teilung verlief die Grenze entlang der Weichsel und Österreich plante, auf seinem Gebiet eine modern angelegte Stadt (Ludwinów) zu gründen, die eine Konkurrenz zu Krakau bilden sollte. Nach der dritten Teilung fiel Krakau an die Habsburger Monarchie, und damit wurden ähnliche zivilisatorische Maßnahmen wie in Posen eingeführt, vor allem die Sanierung des Stadtgebietes und die Schleifung der alten Stadtmauer. Vom Kaiser wurde die Anlegung der Promenade (Planty) und einer Ringstrasse verordnet. Dies war eine Voraussetzung für die weitere Entwicklung dieses Stadtteils zu einer Bühne der bürgerlichen, städtischen und teilweise staatlichen Repräsentation, die viel früher, noch vor der Gründung der Wiener Ringstrasse, als eine modellhafte Anlage auf dem ehemaligen Festungsgelände entstand. Krakau war, besonders nach der Einführung der Autonomie in Galizien um 1867, ein Zentrum der polnischen Nationalbewegung, was sich im städtischen Raum in der Ausformung „national” kodierter Territorien niederschlug ${ }^{38}$. Die frühere königliche Triumphstrasse, die von der St. Floriankirche in der Vorstadt über die Barbakane und das Floriansthor, den Marktplatz zur Wawelanhöhe führte, wurde um 1900 in die neue „nationale Achse” umgebaut. $\mathrm{Zu}$ den wichtigsten Objekten, die auf diesem Weg „patriotische” Stationen bildeten, gehörte die architektonisch neu definierte vorstädtische Platzanlage (heute plac Jana Matejki). Dort befand sich nicht nur die staatliche Eisenbahndirektion, sondern auch die für Krakauer viel wichtigeren Objekte wie die Hochschule der bildenden Künste (wo

37 Vgl. M. Marek, Universität als „Monument” und Politikum. Die Repräsentationsbauten der Prager Universitäten 1900-1935 und der politische Konflikt zwischen, „konservativer” und „moderner” Architektur, München 2001, S. 19-44. J. Pešek, Od aglomerace $k$ velkomestu: Praha a stredoevropske metropole 1850-1920 [Von der Agglomeration zur Großstadt. Prag und die mitteleuropäischen Metropolen 1850-1920], Praha 1999, S. 154, 155; K. Bečková (Hg.), Pražská asanace: $k$ 100. výročí vydání asanačního zákona pro Prahu, Praha 1993.

38 J. Purchla, Matecznik Polski. Pozaekonomiczne czynniki rozwoju Krakowa w okresie autonomii galicyjskiej, Kraków 1992. 


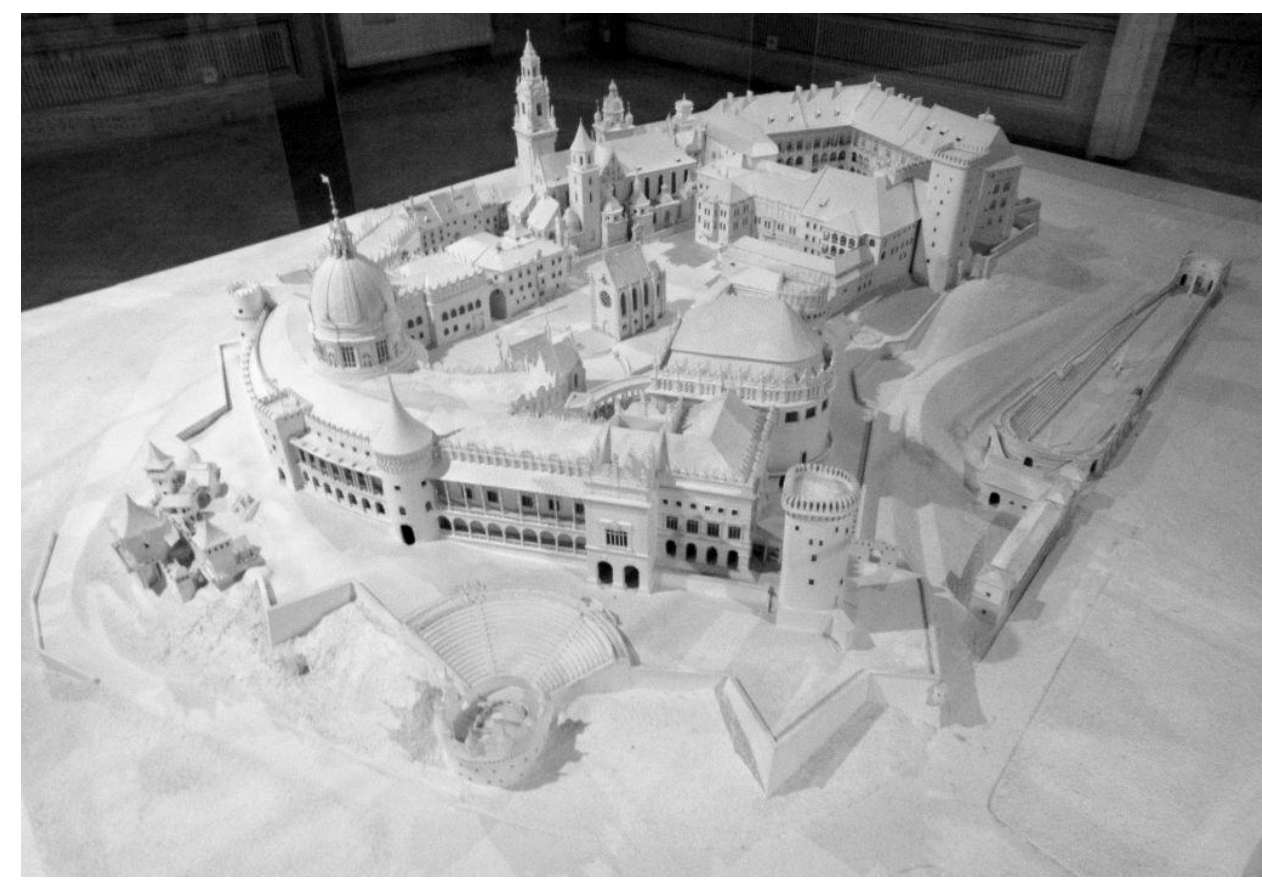

8. Krakau, Akropolis, Entwurf von Wyspiański und Ekielski, Gesamtansicht. Model. Fot. Agnieszka Zabłocka-Kos 2013

Jan Matejko residierte) und das 1910 enthülltes Tannenbergdenkmal. Auf dem Altstadtgelände markierte das Czartoryskimuseum mit der prächtigen privaten Sammlung (Bilder von Leonardo da Vinci und Rafael) den wichtigsten symbolischen Punkt dieser Achse. Einen Höhepunkt des Weges bildete der Marktplatz (Rynek) mit der mittelalterlichen Tuchhalle in der Mitte, die - um 1860 als Pantheon der Polen konzipiert - ab 1879 ein Nationalmuseum beherbergte. Den Eingangsbereich verzierte das zweite patriotische Denkmal, Mickiewicz gewidmet (Enthüllung 1898). Der Weg endete auf dem Wawelhügel - dem wichtigsten Ort der polnischen nationalen Identität, wo die Burg - Stammsitz der polnischen Könige - und die Kathedrale mit den Herrscher- und Heldengräbern die Anhöhe krönten. Unmittelbar nach der Annexion, 30 Jahre existierenden Freien Stadt Krakau, im Jahre 1846 durch Österreich wurden der Wawelhügel in eine Festung und das Schloss in eine österreichische Kaserne umgewandelt. 1880 schenkten jedoch die Stadtväter Franz Joseph die Burg als Privatresidenz ${ }^{39} .1900$ wurde das

39 Wawel narodowi przywrócony. Odzyskanie zamku i jego odnowa 1905-1939, Kraków 2005 (Katalog der Ausstellung), M. Podlodowska-Reklewska (Hg.), S. 18-85. 
Kościuszkodenkmal gegossen, das die Einfahrt zur Kathedrale verzieren und diese nationale Via Triumphalis krönen sollte. Seine Aufstellung wurde jedoch nicht gestattet. Im Zusammenhang mit der Räumung des Wawelhügels von Militäreinrichtungen entwarf Stanisław Wyspiański, der bedeutendste polnische Künstler der damaligen Zeit, zusammen mit dem Architekten Władysław Ekielski einen Umbauplan der Wawelburg in die "polnische Akropolis" (1904)40. Das Projekt, als Stadtkrone gedacht, sollte einen Mittelpunkt nicht nur der vor kurzem entfestigten Stadt, sondern symbolisch eine Krone des nicht existierenden Staates sein. Die Renaissanceformen, als Nationalstilistik verstanden und an das alte Königsschlosses anknüpfend, verbanden symbolisch die Gegenwart mit der glorreichen Vergangenheit der Rzeczpospolita. Die Verwirklichung der Idee von Wyspiański schien durchaus möglich, da Galizien sich unter Franz Josephs Herrschaft einer unvergleichlich größeren Autonomie als die sonstigen Teilungsgebiete erfreute. Besonders in Krakau, das kein Regierungssitz war, blühte das künstlerische, wissenschaftliche und politische Leben. In diesem Zusammenhang bildete die polnische Wawel-Akropolis in Krakau eine Quintessenz des symbolisch-politischen polnischen Gebiets ${ }^{41}$. Der Wawel als Wiege des polnischen Staatswesens sollte die für die Existenz der Nation wichtigsten Funktionen vereinen: das Parlament, verbunden mit dem Sitz des Königs und des Oberhauptes der katholischen Kirche sowie dem Zentrum der Wissenschafts- und Kunsteinrichtungen. Die jahrtausendlange Verbindung mit der europäischen Kultur sollte das griechische Theater betonen, von dem sich ein Blick auf die Tatra erstrecken würde - die polnische Gebirgskette, deren Bevölkerung - Goralen - als Stammväter des polnischen Volkes galten. Das Akropolisprojekt wäre als ein symbolischer Gegenbau zur Posener Hohenzollernburganlage und zur russischen Nevskij Kathedrale in Warschau interpretiert worden, von Polen für Polen im polnischen Nationalstil errichtet und mit polnischen Institutionen höchsten Ranges versehen. Der Entwurf wurde nicht umgesetzt, blieb jedoch lange im kollek-

40 S. Wyspiański, W. Ekielski, „Akropolis”. Pomyst zabudowania Wawelu obmyśleli Stanisław Wyspiański i Władysław Ekielski w latach 1904-1908, „Architekt”, Jg. 9, Heft 5-6, 1908, S. 49-57.

41 J. Krawczyk, Mesjanistyczna architecture parlante Stanisława Wyspiańskiego, „Ikonotheca” Prace Instytutu Historii Sztuki Uniwersytetu Warszawskiego, Jg. 1, (1990), S. 25; K. Nowakowska-Sito, Między Wawelem a Akropolem. Antyk i mit w sztuce polskiej przełomu XIX i XX wieku, Warszawa 1996, S. 159-179. Vgl. auch: Wyspiański, Kazandzakis i modernistyczne wizje antyku, M. Borowska. M. Kalinowska, P. Koniecki (Hg.), Warszawa 2013. 
tiven Gedächtnis haften und beeinflusste die Umbauprojekte des Wawelhügels nach dem Ersten Weltkrieg.

Zusammenfassend lässt sich konstatieren: In den polnischen Städten, die sich unter verschiedenen fremden Herrschaften befanden, wurden im Laufe des 19. Jahrhunderts und besonders vor dem Ersten Weltkrieg architektonisch-städtebauliche Projekte unternommen, die die jeweilige Staatsmacht demonstrativ verstärken und im öffentlichen Stadtraum versinnbildlichen sollten. Die Zuspitzung der kolonialartigen Herrschaft führte, wie von Stachel angedeutet wurde, zu „Mehrfachbeanspruchungen (...) und manchmal ausgesprochen feindselig gegeneinander gerichteten Lesearten". Neue, vom Staat finanzierte Bauten konnten die besten städtischen Räume annektieren und dadurch in der städtebaulichen Struktur eine Rolle der architektonischen fremden Dominante spielen. Dies geschah vor allem in den Großstädten im preußischen bzw. russischen Teil Polens. Als Antwort darauf versuchte die polnische Bevölkerung, das politisch geprägte Territorium auf eigene Art und Weise zu markieren. Damit entstand eine architektonische „Kakofonie", die die Dissonanzen des politischen, gesellschaftlichen und ethnischen Lebens widerspiegelte.

\section{ARCHITECTURE AND URBAN PLANNING IN THE PARTITIONED POLAND OF THE $19^{\text {TH }}$ CENTURY IN POLITICAL CONTEXT}

\section{Summary}

The essay focuses on the history of nineteenth-century architecture in Polish lands, including analyses of selected buildings in Poznań, Warsaw, and Cracow, considered in the context of "political architecture" and "political urban spaces", and in reference to Prussian, Russian, and Austro-Hungarian policies of "internal colonization." The author presents the strategies of political and social elites (both Polish and foreign), implementing by specific buildings the ideas of dominating and appropriating public spaces as well as politically and ideologically significant selfrepresentation. The architecture of city centers has been presented in terms of binary oppositions: buildings constructed in response to the already existing ones and changing functions of older structures in the three cities in question have been compared, their meanings and counter-meanings deciphered, and the creation of public spaces with overlapping or mutually exclusive symbolism discussed. Buildings erected by the occupants, interpreted by Poles as manifestations of their power, often provoked Polish reaction, i.e. the construction of other buildings which demonstrated resistance through style and decoration. That unique kind of encoding introduced new hierarchies into urban spaces in which Polish and foreign investors kept searching for their 
symbolic architectural idioms. Each of the historical periods in the nineteenthcentury history of Polish cities contributed to their public spaces specific buildings which created a unique architectural palimpsest that can be interpreted in different ways. Each political, social or cultural modification of such palimpsests resulted in a new picture so that the public space kept changing like in a kaleidoscope. Each move (a new building, reconstruction or change of decoration) resulted in irreversible changes of meaning. Thus, the ever-changing city created unique architectural and urban cityscapes - "unwritten records" which can be deciphered and interpreted to expand our knowledge of the history of a given territory and the Polish people. 